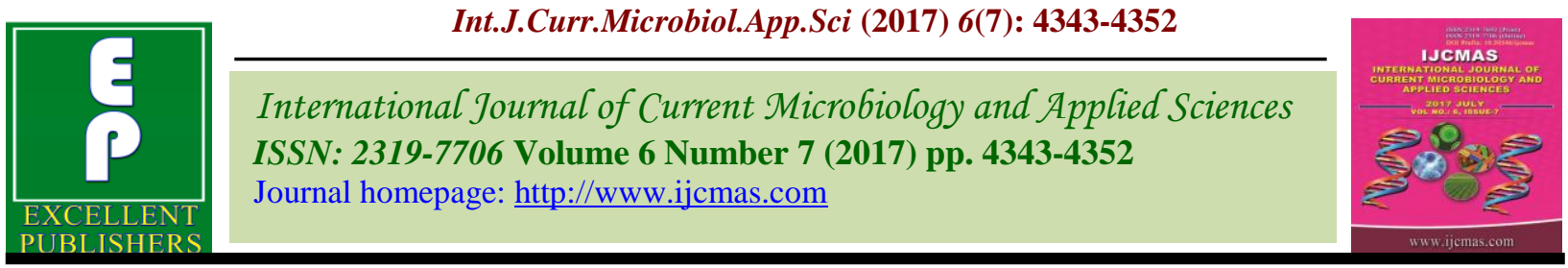

Original Research Article https://doi.org/10.20546/ijcmas.2017.607.452

\title{
Microbiological Profile of External Ocular Infections in a Tertiary Care Hospital in South India
}

\author{
S. Rajesh, B. Divya* and V.Aruna \\ Government Mohan Kumaramangalam Medical College Salem, Tamil Nadu, India \\ *Corresponding author
}

\section{A B S T R A C T}

\section{Keywords}

Bacterial isolates, External ocular infections, Drug susceptibility pattern.

Article Info

Accepted:

30 June 2017

Available Online:

10 July 2017
The eye may be infected from external sources or through intra-ocular invasion of microorganisms carried by the blood stream ${ }^{[1]}$. Bacteria are the major cause of ocular infections ${ }^{[2]}$. This study was undertaken to isolate and identify the microorganisms causing external ocular infections and to determine the in-vitro susceptibilities of bacteria to commonly used antibacterial agents. A cross sectional study was conducted among 110 patients with external ocular infections at Govt. Mohan kumaramangalam medical college hospital, Salem over a period of 6 months from July to December 2016.Socio-demographic and clinical data were collected using structured questionnaire. External ocular specimens were collected using sterile swabs and inoculated on mac conkey agar, chocolate agar, blood agar, mannitol salt agar and sabouraud's dextrose agar culture Medias. Presumptive isolates were further identified by a series of biochemical tests. The antimicrobial susceptibility patterns of the isolates were determined by disc diffusion method. Out of 110 samples processed only 54(49\%) showed growth. The overall prevalence of bacterial pathogens among external ocular samples was $46.3 \%(\mathrm{n}=51 / 110)$ and of fungal pathogens was $2.7 \%(n=3 / 110)$. The majority of the isolates $(67 \% ; 36 / 54)$ were Gram positive bacteria and $28 \%(15 / 54)$ Gram negative bacteria. The percentage of fungal isolates i.e., Candida spp. was $5 \%(\mathrm{n}=3 / 54)$. The proportion of Staphylococcus aureus was $47 \%(n=24 / 51)$ and Coagulase negative Staphylococci was $23.5 \%(n=12 / 51)$ among the Gram positive bacterial isolates. The proportion of Klebsiella spp. is $23.5 \%$ (n $=12 / 51)$ and Pseudomonas aeruginosa 5.8\% $(\mathrm{n}=3 / 51)$ among the Gram negative bacterial isolates. All Gram positive isolates were susceptible to vancomycin. Majority of the Gram negative bacterial isolates showed susceptibility to ofloxacin and ciprofloxacin. The prevalence of bacterial pathogens among external ocular samples was high and the predominant isolate was Staphylococcus aureus. Conjunctivitis was found to be the dominant infection.

\section{Introduction}

The eye is a unique organ that is impermeable to almost all external organisms. Continuous tear flow, aided by the blink reflex, mechanically washes substances from the ocular surface and prevents the accumulation of microorganisms. In addition, lysozyme, lactoferrin, secretory immunoglobulin's, and defensins, which are present at high levels in tears, can specifically reduce bacterial colonisation of the ocular surface ${ }^{[3,4]}$. The eye may be infected from external sources or through intra ocular invasion of microorganism caused by blood stream [1] Pathogenic micro-organisms cause ocular 
disease and the most frequently affected parts of the eye are the conjunctiva, lid and cornea ${ }^{[6]}$. Bacteria are major causative agents that frequently cause infections in eye and possible loss of vision ${ }^{[2]}$.Frequently reported clinical manifestations include conjunctivitis, scleritis, keratitis, blepharitis, canaliculitis and dacryocystitis ${ }^{[6]}$. Conjunctivitis is the most common cause of "red eye" [14] and corneal ulceration is a major cause of mono-ocular blindness in developing countries ${ }^{[14]}$. The three most common causes of conjunctivitis are infections (infective conjunctivitis), allergic reactions and irritation (loose eyelash). Infective conjunctivitis is most commonly caused by bacteria and viruses. Viral conjunctivitis causes a watery discharge while the discharge from bacterial conjunctivitis contains pus [16]. Infective keratitis is a major cause of vision loss and blindness second to cataract $[3,4]$. Ocular trauma is a far more common predisposing factor of infectious keratitis in developing countries, whereas pre-existing ocular disease and wearing contact lens are common risk factors in developed countries ${ }^{[25]}$. Blepharitis is an inflammation of the eyelid margins which can result in patient discomfort and decline in visual function ${ }^{[19]}$. Dacryocystitis is an inflammation of the lacrimal sac and duct $^{[20,21]}$.

Ocular Infections caused by the bacteria is most common which is followed by fungal and then viral infections. The bacterial aetiology and their susceptibility as well as resistant patterns may vary with geographical location according to the local population [8], [9], [10], [11], [12], [13]. Bacteria cultured from the conjuctival sac are usually similar to those found in the upper respiratory tract and the skin, with majority being Gram positive bacteria and commonly Staphylococcus spp. and Corynebacterium spp. In addition the eyelid margins and conjuctival sacs of healthy subjects can also contain Gram negative pathogens [24]. Aspergillus spp. and Staphylococcus aureus are the most common fungus and bacteria isolated frequently. These infections if not treated promptly may lead to complications. The morbidity due to ocular infections can vary from self-limiting, trivial infection to sight threatening condition and blindness ${ }^{[22]}$. A variety of factors determine clinical outcome in microbes causing eye infection and the epidemiological patterns vary from one country to the other and in different geographical areas in the same country ${ }^{[23]}$. The ability to isolate the causative organism depends on a variety of factors including the amount of inoculum, the site from which it is taken, the media used for culture (whether enriched media are used or not) and also on the empirical treatment received before collection of the samples. If they are not treated properly it may lead to sight threatening condition.

The management of bacterial eye infections may involve treatment with broad spectrum antibiotics. The indiscriminate use of antibiotics led to the development of resistance to many commonly used antimicrobial medications. The emergence of bacterial resistance towards topical antimicrobial agents may increases the risk of treatment failure with potentially serious consequences ${ }^{[7]}$. Therefore, up to date information is essential for appropriate antimicrobial therapy and management of ocular infections ${ }^{[23]}$. Thus, the aim of this study is to identify the dominant bacterial pathogen common to external ocular infections, and to assess the in vitro drug susceptibility patterns of these isolates to commonly prescribed antibiotics among patients with external ocular infections.

\section{Materials and Methods}

A cross-sectional study was conducted from July to December 2016 at Govt. Mohan 
Kumaramangalam Medical College Hospital, Salem. All patients who had signs and symptoms of external ocular infections were included as study population. One hundred and ten consecutive patients attending the ophthalmology outpatient department of the hospital from July to December 2016 were included in this study.

Patients who had treatment with antibiotics within the last 5 days or who had undergone previous ocular surgery within the last 7 days of recruitment of study subjects were excluded from the study.

\section{Sample collection and laboratory investigation}

\section{Sample collection}

After detailed eye examination, using standard techniques external ocular specimens were collected for culture and smears were obtained by scraping and swabbing the eyelid margin using sterile blade or Bard Parker handle and sterile broth moistened cotton swabs in case of conjunctivitis and blepharitis. Corneal/Conjuctival scraping and swabbing were performed and subjected to direct microscopy and culture.

Briefly, patient was requested to look up, lower eye lid was pulled down and then swabs were collected. The sample collector holds the palpebra apart and gently collects discharge from the surface of the eye using sterile cotton swab that has been premoistened with sterile saline. The sterile normal saline moistened swab was rubbed over the lower conjunctival sac from medial to lateral side and back again. Purulent material in cases of dacryocystitis was collected by everted puncta then applying pressure over the lacrimal sac area from the infected eye ${ }^{[26,27]}$. The swab was immersed in $3 \mathrm{ml}$ of brain heart infusion (BHI), placed in a cold box and transported to the laboratory for investigation.

\section{Isolation and identification of bacterial pathogens}

Specimens were subjected to (10\% potassium hydroxide) wet mounting \& Gram staining as first step and microbial culture identification was done by inoculating the specimens on to mac conkey agar, mannitol salt agar, blood agar, chocolate agar and sabouraud's dextrose agar plates and incubated at $37{ }^{\circ} \mathrm{C}$ for 48 hours. All plates were initially examined for growth after 24 hours and cultures with no growth were incubated for further 48 hours. After getting pure colonies, further identification was done using standard microbiological techniques, which includes Gram stain, colony morphology and biochemical tests.

Presumptive Gram negative bacteria were identified using triple sugar iron agar, citrate utilization test, urease test and indole test and Gram positive bacteria were identified using catalase, coagulase, bacitracin and optochin tests ${ }^{[28]}$. Antimicrobial susceptibility test was carried out on each identified bacterium using disc diffusion method on Muller Hinton agar based on clinical and laboratory standard institute (CLSI) guidelines.

Briefly, 3-5 colonies of the test organism were emulsified in $5 \mathrm{ml}$ of nutrient broth and mixed gently. The suspension was incubated at $37^{\circ} \mathrm{C}$ until the turbidity of the suspension becomes adjusted to $0.5 \mathrm{McF}$ arland standards. The suspension was uniformly rapped on to Mueller-Hinton agar for non-fastidious organisms and Mueller-Hinton agar with defibrinated sterile sheep blood $(10 \% \mathrm{~V} / \mathrm{V})$ for fastidious organisms.

The antimicrobial impregnated disks were placed using sterile forceps on the agar 
surface and the plates were incubated at $37{ }^{\circ} \mathrm{C}$ for 24 hours and the zone of inhibition was determined.

All specimens were collected following standard operating procedure for ophthalmic specimen collection. The sterility of culture media was ensured by incubating $5 \%$ of each batch of the prepared media at $37{ }^{\circ} \mathrm{C}$ for 24 hours.

Performances of all prepared media were also checked by inoculating standard-strains such as Escherichia coli (ATCC 25922), Staphylococcus aureus (ATCC 25923) and Pseudomonas aeruginosa (ATCC 27853). The qualities of biochemical testing procedures were checked by these reference strains.

Microbial cultures were considered significant if growth of the same organisms were demonstrated on more than one solid phase medium and/or if there was confluent growth at the site of inoculation on one solid medium, and/or if growth of one medium to be consistent by direct microscopy findings and/or if the same organism was grown from repeated specimens. The isolated strains were identified upto species level by standard biochemical steps.

\section{Results and Discussion}

\section{Socio-demographic characteristics of the study participants}

A total of 110 patients were enrolled in this study. The majority of the study subjects were males $(74 / 110 ; 67.2 \%)$.

The mean age of the study participants was $55.11(\mathrm{SD} \pm 17.85)$ years. Most of the study participants were illiterate $(82 / 110,74.5 \%)$, majority $(85 / 110,77.2 \%)$ were rural dwellers and $(72 / 110,65.4 \%)$ were farmer by occupation.

\section{Clinical findings}

In this study, $42.7 \%(47 / 110)$ patients were suffering from conjunctivitis followed by keratitis $28.1 \%,(31 / 110)$ as shown in chart 4. The dominant type of ocular infection among male patients was conjunctivitis (44/74; $59.4 \%$ ) where as in female patients a higher number of cases of dacryocystitis (41.6\%; 15/36) was observed.

When the different types of eye infection were stratified by sex, higher prevalence of conjunctivitis cases were observed among male patients than females but the prevalence of dacryocystitis was higher among female patients.

\section{Prevalence of bacterial pathogens and} associated risk factors

Out of 110 samples processed only 54(49\%) showed growth. The overall prevalence of bacterial pathogens among external ocular samples was $46.3 \% \quad(\mathrm{n}=51 / 110)$. The majority of the isolates $(67 \% ; 36 / 54)$ were Gram positive and $28 \%$ (15/54) Gram negative bacteria. The percentage of fungal isolates i.e., Candida spp. was $5 \%(\mathrm{n}=3 / 54)$. The proportion of Staphylococcus aureus was $47 \%(\mathrm{n}=24 / 51)$ and Coagulase negative Staphylococci was $23.5 \%(\mathrm{n}=12 / 51)$ among the Gram positive bacterial isolates.

The proportion of Klebsiella spp. is $23.5 \%$ (n $=12 / 51)$ and Pseudomonas aeruginosa $5.8 \%$ $(\mathrm{n}=3 / 51)$ among the Gram negative bacterial isolates. The details are shown in chart 1, 2 \&3. In this study, occupation, residence, education, frequency of face washing, the occurrence of systemic disease like diabetes mellitus, usage of contact lens, steroid abuse, history of trauma prior to infection and cigarette smoking were used as possible risk and predisposing factors for ocular infections. 
Antimicrobial susceptibility patterns of bacterial isolates

The antimicrobial susceptibility patterns of bacterial isolates from ophthalmic patients showed that a significant number of bacterial isolates were resistant to one or more than one antimicrobials. All Gram positive isolates were susceptible to vancomycin $(100 \%)$ with cefoxitin $(92 \%)$. The number of isolates of Staphylococcus aureus showing susceptibility to amikacin 18(75\%), gentamicin 23(96\%), cotrimoxazole $20(83.3 \%)$, ciprofloxacin $10(42 \%)$. The number of isolates of Coagulase negative Staphylococci showing susceptibility to amikacin 4(33\%), gentamicin $3(25 \%)$, cotrimoxazole 5(42\%), ciprofloxacin 9(75\%). 2/24 isolates of Staphylococcus aureus were MRSA and 1/12 isolates of Coagulase negative Staphylococci was MR CoNS. In case of Gram negative bacterial isolates most of them showed susceptibility to ofloxacin and ciprofloxacin. All the 3 (100\%) isolates of Pseudomonas aeruginosa showed susceptibility to ofloxacin and ciprofloxacin with susceptibility to gentamicin $2(67 \%)$, tetracycline 1(33.3\%), amikacin 2(67\%) and cefotaxime $2(67 \%)$. The number of isolates of Klebsiella spp. showing susceptibility to ofloxacin 11(92\%), ciprofloxacin 10(83.3\%), gentamycin 2(67\%), amikacin $0(0 \%)$, cefotaxime $0(0 \%)$, tetracycline $0(0 \%)$. The details are shown in tables 1 and 2.

The organisms that cause ocular infection are generally exogenous. However, in certain circumstances they gain accesses to enter the eye and cause infection. In this study, the prevalence of bacteria causing eye infection was $46.3 \%$ and it is slightly lower when compared with other previous study reports from Gondar, India and Ethiopia (60.8\%, and $58.8 \%, \quad 59.4 \%$ respectively) $[29,30,31]$. Majority of the patients were rural dwellers and farmer by occupation as reported in study from Ethiopia ${ }^{[31]}$.

Table.1 In vitro antimicrobial susceptibility pattern of Gram positive bacterial isolates

\begin{tabular}{|l|l|l|l|l|l|l|}
\hline & VAN & FOX & AK & GEN & COT & CIP \\
\hline S.aureus & $24(100 \%)$ & $22(92 \%)$ & $18(75 \%)$ & $23(96 \%)$ & $20(83.3 \%)$ & $10(42 \%)$ \\
\hline CoNS & $24(100 \%)$ & $11(92 \%)$ & $4(33 \%)$ & $3(25 \%)$ & $5(42 \%)$ & $9(75 \%)$ \\
\hline
\end{tabular}

VAN-Vancomycin, FOX-Cefoxitin, AK-Amikacin, Gen- Gentamycin, COT-Cotrimoxazole, CIP-Ciprofloxacin

Table.2 In vitro antimicrobial susceptibility pattern of Gram negative bacterial isolates

\begin{tabular}{|l|l|l|l|l|l|l|}
\hline & AK & CTX & CIP & OF & TE & GEN \\
\hline Pseudomonas aeruginosa & $2(67 \%)$ & $2(67 \%)$ & $3(100 \%)$ & $3(100 \%)$ & $1(33.3 \%)$ & $2(67 \%)$ \\
\hline Klebsiella spp. & $0(0 \%)$ & $0(0 \%)$ & $1(33.3 \%)$ & $3(25 \%)$ & $0(0 \%)$ & $2(67 \%)$ \\
\hline
\end{tabular}

AK-Amikacin, CTX-Cefotaxime, CIP - Ciprofloxacin, OF- Ofloxacin, TE - Tetracycline, GEN - Gentamycin 
Chart.1 Percentage of culture positivity in ocular specimens

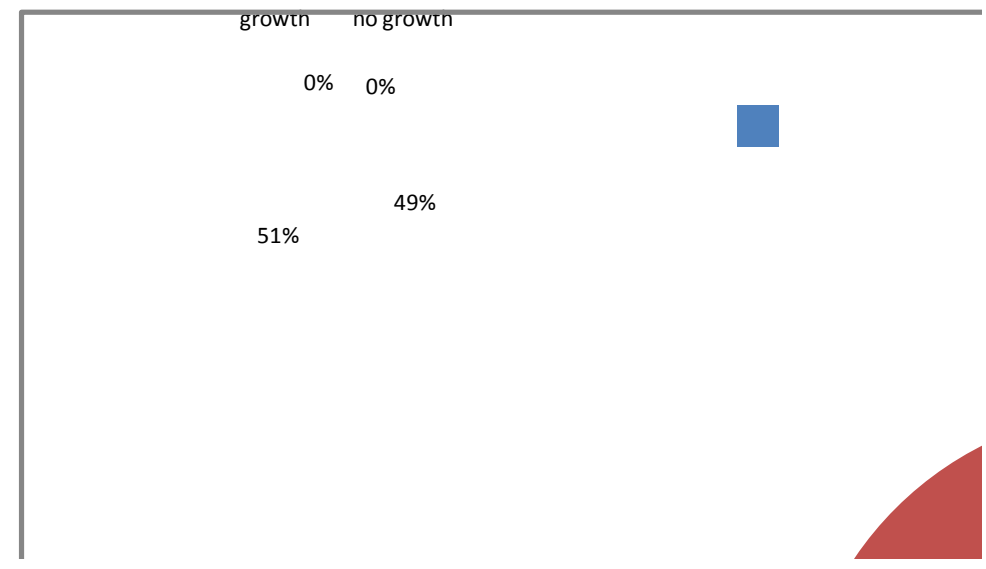

Chart.2 Percentage of different microbial flora grown in culture

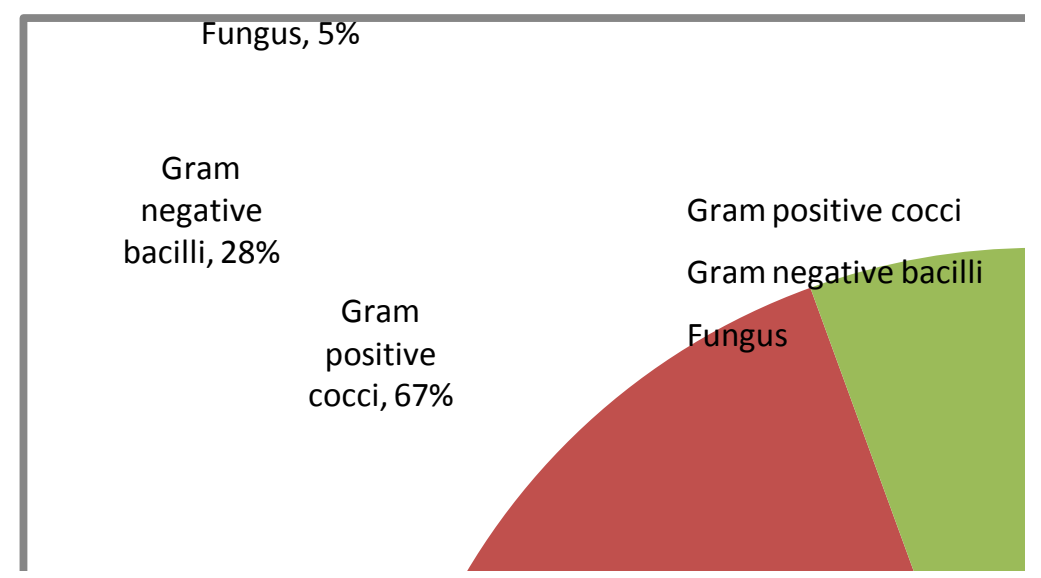

Chart.3 Distribution of different pathogens grown in culture

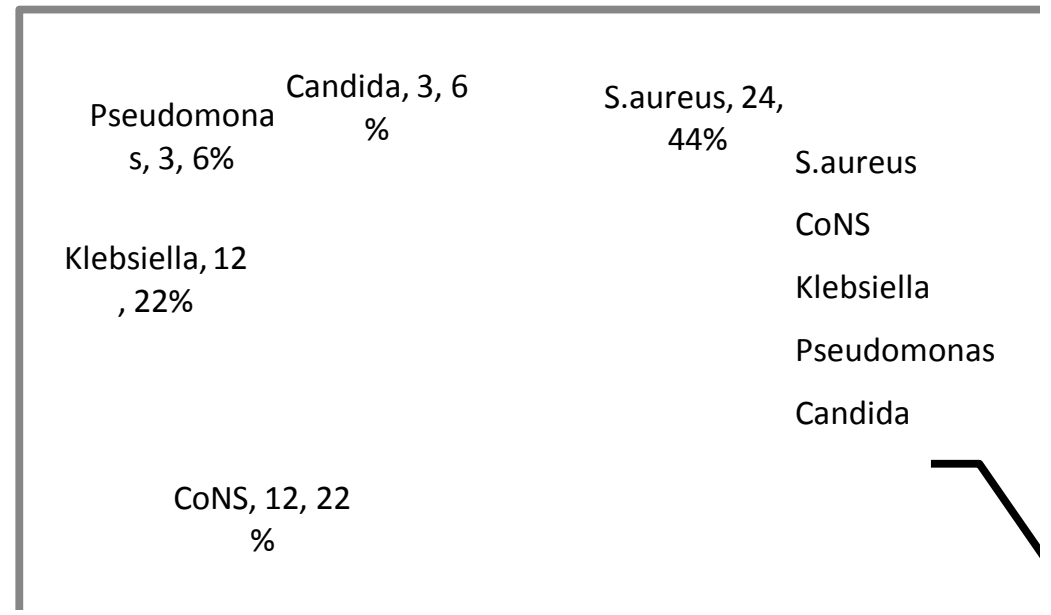




\section{Chart.4 Prevalence of different types of external ocular infections}

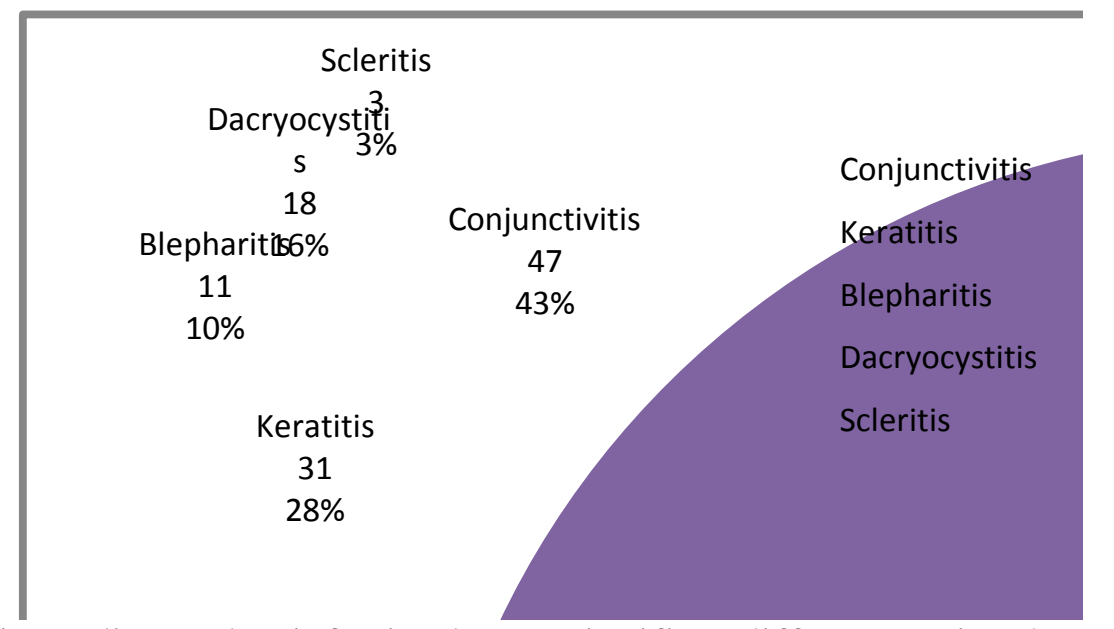

The conjunctiva is predisposed to infection by diverse micro-organisms. The principal routes of inoculation are airborne droplets, hand-toeye contact, and spread from the ocular adnexa, including the lacrimal system, nose, and paranasal sinuses ${ }^{[36]}$ In the current study, conjunctivitis (43\%) is the dominant type of eye infection followed by keratitis (31\%), blepharitis (11\%), dacryocystitis (18\%) and scleritis 3(\%) similar to the study conducted by Birtukan et al., ${ }^{[31]}$ where conjunctivitis was the dominant type of eye infection (43.1\%).

In this study the dominant type of ocular infection among male patients was conjunctivitis $(44 / 74 ; 59.4 \%)$ where as in female patients a higher number of cases of dacryocystitis $(41.6 \%$; 15/36) were observed. Higher rates of both acute and chronic dacryocystitis have been reported in previous studies among women [32, 33]. Data of the current study showed that external ocular infections were predominantly seen among male patients. This might be due to their outdoor activities and that was also supported by similar reports from Jimma and Gondar, Ethiopia ${ }^{[2,34]}$.

The occurrence of different bacteria as an etiological agent for external ocular infection

signifies differences in the environmental conditions, the standard of personal hygiene, age and the site of infection. Hence, the culture positivity varies from centre to centre. In this study, the overall culture-positivity was $49 \%$. Bacteria $(95 \%)$ were the most common pathogens and were involved in infections of all the tissues of the eye, whereas fungi $(5 \%)$. The majority of the isolates $(70.5 \% ; 36 / 51)$ were Gram positive and the other $29.4 \%(15 / 51)$ were Gram negative bacteria. Staphylococcus aureus $(44 \%)$ is the predominant bacterial pathogen isolated in this study similar to the study conducted in south India by Ramesh et al., [35].

The prevalence of $S$. aureus in causing conjunctivitis has been reported to be higher in many parts of the world ${ }^{[37],[38],[39]}$.It is also inferred that $8.3 \%$ of the staphylococci isolated were MRSA and $8.3 \%$ of CoNS were MR - CoNS. The prevalence of Gram negative bacteria as etiological agents of ophthalmic disease in the current study can be graded lower as only $28 \%(n=15 / 54)$ of the patients who were positive for these bacterial pathogens. This decrease in prevalence could be due to the effective personal hygiene. Most of the ocular bacterial infections are due to Gram positive bacteria than Gram negative bacteria. The present 
study mainly focused on Gram positive cocci causing eye infections. Several other studies in India, Nepal and other parts of world have shown similar results inferring Gram positive cocci as a primary cause of ocular infections.

The relationship between antibiotic use and resistance is complex. Improper selection of antibiotics, inadequate dosing and poor compliance to the therapy may play an important role in increasing resistance as their overuse.

The analysis on in-vitro susceptibility testing shows that vancomycin demonstrated greatest efficacy against Gram-positive isolates alone, while ciprofloxacin and ofloxacin demonstrated greatest efficacy against Gramnegative isolates. Frequent and routine use of antibiotics for all bacterial ocular infections in our population has decreased susceptibility to most of the tested antibiotics. Besides that, all fluoroquinolones tested in this study, ciprofloxacin and ofloxacin showed higher efficacy against Gram negative bacterial isolates and proving that in our community quinolones, especially ciprofloxacin and ofloxacin are a good choice for treating ocular infections at present. The information provided in this article would aid the clinician in formulating rationale-based decisions in the antibiotic treatment of bacterial ocular infections that cause major public health problems.

In conclusion, the prevalence of bacterial infection among patients with external ocular infection in this study was high $(46.3 \%)$. The predominant isolates were Staphylococcus aureus, Coagulase negative staphylococci and Klebsiella spp. High antibiotic resistance to commonly prescribed antibiotics was observed. Methicillin resistance has been observed in both of the Gram positive isolates, Staphylococcus aureus \& Coagulase negative Staphylococci for which vancomycin showed $100 \%$ susceptibility. Gram negative bacterial isolates showed resistance to amikacin, cefotaxime and tetracycline. Quinolones showed promising results in the treatment of Gram negative pathogens.

Therefore, to prevent the increasing rate of antimicrobial resistance the practice of starting empirical therapy to be avoided and the routine identification of bacteria through culture methods and conducting drug susceptibility testing should be practiced in addition to direct Gram staining and potassium hydroxide wet mounting, as a routine diagnostic procedure especially in the centres where ophthalmologists have access to microbiology lab facilities.

Improper selection of antibiotics, inadequate dosing and poor compliance to therapy may play an important a role in increasing resistance. Changes in bacterial resistance patterns have been a major problem in the effective management of ocular infections, better access to effective and safe topical antibiotics has been cited as the primary factor in improving patients outcomes and quality of life. Early access to diagnosis and appropriate treatment and better patient health education can prevent the ocular morbidity and mortality.

\section{References}

1. Williamson-Noble FA, Sorsby A. Etiology of the eye diseases; developmental defects; heredity. In: Conrad B, editor. The Eye and Its Diseases. 2nd ed. Philadelphia: W. B. Saundars Company; 1950. pp. 309-21.

2. Tesfaye T, Beyene G, Gelaw Y, Bekele S, Saravanan M. Bacterial Profile and Antimicrobial Susceptibility Pattern of External Ocular Infections in Jimma University Specialized Hospital, Southwest Ethiopia. Am J Ophthalmol. 2013;1:13-20. 
3. Haynes RJ, Tighe PJ, Dua HS. Antimicrobial defensin peptides of the human ocular surface. Br J Ophthalmol 1999; 83:737-41.

4. McClellan KA. Mucosal defense of the outer eye. Surv Ophthalmol 1997; 42:233-46.

5. Williamson-Noble FA, Sorsby A. Etiology of the Eye Diseases; Developmental Defects; Heredity. In: Conrad B, editor. The Eye and Its Diseases, $2^{\text {nd }}$ ed. Philadelphia: W. B. Saundars Company; 1950.p309-321.

6. Ramesh S, Ramakrishnan R, Bharathi M, Amuthan M, Viswanathan S. Prevalence of bacterial pathogens causing ocular infection in south India. Indian J Pathol Microbiol. 2010;53(2):281-6.

7. Sharma S. Antibiotics and Resistance in Ocular Infections. Indian J Med Microbiol. 2011;29:218-22

8. Carmichael TR, Wolpert M, Koornhof HJ. Corneal ulceration at an urba African hospital. Br J Ophthalmol 1985;69:920-6.

9. Liesegang TJ, Forster RK. Spectrum of microbial keratitis in South Florida. Am J Ophthalmol 1980;90:38-47.

10. Kowalski RP, Karenchak LM, Romanowski EG. Infectious disease: changing antibiotic susceptibility. Ophthalmol Clin N Am 2003;16:1-9.

11. Chalita MR, Hofling-Lima AL, Paraanhos A Jr, Schor P, Belfort R Jr. Shifting trends in in-vitro antibiotic susceptibilities for common ocular isolates during a period of 15 years. Am J Ophthalmol 2004;137:43-51.

12. Ooishi M, Miyao M. Antibiotic sensivity of recent clinical isolates from patients with ocular infections. Ophthalmologica 1997;211:15-24.

13. Benz MS, Scott IU, Flynn HW, Unonius N, Miller D. Endophthalmitis isolates and antibiotic sensitivities: A 6-year review of culture-proven cases. Am J Ophthalmol 2004;137:38-42.

14. Sthapit PR, Tuladhar NR, Marasini S, Khoju U, Thapa G. Bacterial Conjunctivitis and Use of Antibiotics in
Dhulikhel Hospital - Kathmandu University Hospital. Kathmandu Univ Med J. 2011;9:69-72.

15. Whitcher JP, Srinivasan M, Upadhyay MP. Corneal blindness: a global perspective. Bull World Health Organ. 2001;79:214-21.

16. Marilyn $\mathrm{H}$ and Charles S. Conjunctivitis: Bacterial, Viral, Allergic and Other Types. All about vision.com. Access Media group LLC, March 2014.

17. Sinha R, Sharma N, Vajpayee RB. Corneal Blindness - Present Status. Cataract \& Refractive Surgery Today. 2005;59-61.

18. Lemp MA, Nichols KK. Blepharitis in the United States 2009: a survey-based perspective on prevalence and treatment. TOS. 2009;7:1-14.

19. Azari AA, Barney NP. Conjunctivitis A Systematic Review of Diagnosis and Treatment. JAMA. 2013;310:1721-9.

20. Chaudhry IA, Shamsi FA, Al-Rashed W. Bacteriology of chronic dacryocystitis in a tertiary eye care center. Ophthal Plast Reconstr Surg. 2005;21:207-10.

21. Mariotti SP, Pascolini D, RoseNussbaumer J. Trachoma: global magnitude of a preventable cause of blindness. $\mathrm{Br} \quad \mathrm{J}$ Ophthalmol. 2009;93:563-8.

22. Gopinathan U, Sharma S, Garg P, Rao G. Review of epidemiological features, microbiological diagnosis and treatment outcome of microbial keratitis: Experience of over a decade. Indian $\mathbf{J}$ Ophthalmol. 2009;57(4):273-9.

23. Brown L. Resistance to ocular antibiotics: an overview. Clin Exp Optom. 2007;90:258-62.

24. McClellan KA. Mucosal defense of the outer eye. Surv Ophthalmol 1997;42:23346.

25. M.JayaharBharathi, R.Ramakrishnan, C.Shirakeema, Etiological antibacterial susceptibility pattern of communityacquired bacterial ocular infections in $\mathrm{TCH}$ in South India, Indian Journal of Ophthalmology. 
26. Baron EJ, Miller JM, Weinstein MP, Richter SS, Gilligan PH, Thomson Jr RB, et al., A guide to utilization of the microbiology laboratory for diagnosis of infectious diseases: 2013 recommendations by the Infectious Diseases Society of America (IDSA) and the American Society for Microbiology (ASM). Clin Infect Dis. 2013;57:22-121.

27. Sharma S. Diagnosis of infectious diseases of the eye. Eye. 2012;26:177-84.

28. Cheesbrough M. District Laboratory Practice in Tropical Countries Part I. 2nd ed. New York: Cambrige University Press; 2006.

29. Birhane Y, Worku A, Bejiga A, Adamu $\mathrm{L}$, Alemayehu $\mathrm{W}$, Bedri A, et al., Prevalence and causes of blindness and low vision in Ethiopia. Ethiop $\mathrm{J}$ Health Dev. 2007;21:204-10.

30. Muluye D, Wondimeneh Y, Moges F, Nega T, Ferede G. Types and drug susceptibility patterns of bacterial isolates from eye discharge samples at Gondar University Hospital, Northwest Ethiopia. BMC Research Notes. 2014; 7: 292. 22.

31. Birtukan Shiferaw,Baye GelawEmailauthor,Abate Assefa,Yared Assefa, Zelalem Addis.Bacterial isolates and their antimicrobial susceptibility pattern among patients with external ocular infections at Borumeda hospital, Northeast Ethiopia.

32. Ali MJ, Joshi SD, Naik MN, Honavar SG. Clinical profile and management outcome of acute dacryocystitis: two decades of experience in a tertiary eye care center. Semin Ophthalmol. 2015;30(2):118-23.

33. Mills DM, Bodman MG, Meyer DR, Morton AD. The microbiologic spectrum of dacryocystitis: a national study of acute versus chronic infection. Ophthal Plast Reconstr Surg. 2007;23(4):302-6.

34. Nigatu N. Pattern of Microbial agents of External Ocular Infections in Federal Police Hospital And Minilik II Memorial Hospital. Addis Ababa: Ethiopia. Addis Ababa University, Garduation Thesis; 2004

35. S.Ramesh, R.Ramakrishnan, M.JayaharBharathi -The prevalence of Bacterial Pathogen causing ocular infection in South India, Indian journal of Pathology and Microbiology-43(2) 2010.

36. Syed NA, Chandler JW. Bacterial conjunctivitis. In: Tabbara KF, Hyndiuk RA, editors. Infections of the Eye. 2 nd ed. Boston: Little, Brown and Company; 1996. p. 423-31.

37. Boralkar AN, Dindore PR, Fule RP, Bangde BN, Albel MV, Saoji AM. Microbiological studies in conjunctivitis. Indian J Ophthalmol 1989; 37: 94-5.

38. Stenson S, Newman R, Fedukowicz H. Laboratory studies in acute conjunctivitis. Arch Ophthalmol 1982;100:1275-7.

39. Stenson S, Newman R, Fedukowicz H. Conjunctivitis in the newborn: observation on incidence, cause, and prophylaxis. Ann Ophthalmol 1981; 13: 329-34.

\section{How to cite this article:}

Rajesh, B., B. Divya and Aruna, V. 2017. Microbiological Profile of External Ocular Infections in a Tertiary Care Hospital in South India. Int.J.Curr.Microbiol.App.Sci. 6(7): 4343-4352. doi: https://doi.org/10.20546/ijcmas.2017.607.452 